ARTICLE

Received 24 Oct 2013 | Accepted 25 Apr 2014 | Published 27 May $2014 \quad$ DOl: 10.1038/ncomms4949

\title{
Spinel-type lithium cobalt oxide as a bifunctional electrocatalyst for the oxygen evolution and oxygen reduction reactions
}

Thandavarayan Maiyalagan ${ }^{1}$, Karalee A. Jarvis ${ }^{1}$, Soosairaj Therese ${ }^{1}$, Paulo J. Ferreira ${ }^{1}$ \& Arumugam Manthiram ${ }^{1}$

\begin{abstract}
Development of efficient, affordable electrocatalysts for the oxygen evolution reaction and the oxygen reduction reaction is critical for rechargeable metal-air batteries. Here we present lithium cobalt oxide, synthesized at $400^{\circ} \mathrm{C}$ (designated as $\mathrm{LT}-\mathrm{LiCoO}_{2}$ ) that adopts a lithiated spinel structure, as an inexpensive, efficient electrocatalyst for the oxygen evolution reaction. The catalytic activity of $\mathrm{LT}-\mathrm{LiCoO}_{2}$ is higher than that of both spinel cobalt oxide and layered

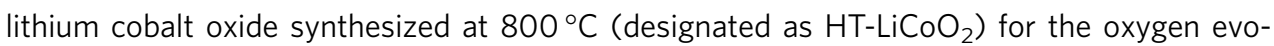
lution reaction. Although $\mathrm{LT}-\mathrm{LiCoO} 2$ exhibits poor activity for the oxygen reduction reaction, the chemically delithiated $\mathrm{LT}_{-} \mathrm{Li}_{1-x} \mathrm{CoO}_{2}$ samples exhibit a combination of high oxygen reduction reaction and oxygen evolution reaction activities, making the spinel-type LT$\mathrm{Li}_{0,5} \mathrm{CoO}_{2}$ a potential bifunctional electrocatalyst for rechargeable metal-air batteries. The high activities of these delithiated compositions are attributed to the $\mathrm{Co}_{4} \mathrm{O}_{4}$ cubane subunits and a pinning of the $\mathrm{Co}^{3+/ 4+}: 3 \mathrm{~d}$ energy with the top of the $\mathrm{O}^{2-}: 2 \mathrm{p}$ band.
\end{abstract}

\footnotetext{
${ }^{1}$ Materials Science and Engineering Program, The University of Texas at Austin, Austin, Texas 78712, USA. Correspondence and requests for materials should be addressed to A.M. (email: manth@austin.utexas.edu).
} 
O xygen electrochemistry plays a major role in energy conversion and storage devices, particularly in the field of fuel cells, metal-air batteries and water electrolysers ${ }^{1-3}$. The major challenge in metal-air batteries and water electrolysis is to design and develop economically feasible, earth-abundant, inexpensive, efficient electrocatalysts for the oxygen evolution reaction $(\mathrm{OER})^{4}$. In nature, water electrolysis is performed by the photosystem II water-oxidizing complex containing $\mathrm{CaMn}_{4} \mathrm{O}_{\mathrm{x}}$ clusters that are capable of promoting water oxidation with significant turnover frequencies at low overpotentials ${ }^{4-8}$. However, it is difficult to use these naturally occurring enzymes in commercial electrochemical devices due to their instability under the operating conditions ${ }^{9}$. Precious-metal electrocatalysts such as $\mathrm{Pt}, \mathrm{IrO}_{2}$ and $\mathrm{RuO}_{2}$ are normally employed, but their low abundance and high cost prohibit their practical use ${ }^{10}$. Pt exhibits inadequate OER activity due to the formation of the insulating platinum oxides. $\mathrm{RuO}_{2}$ becomes unstable at high potentials due to the formation of higher-valent ruthenium oxides. $\mathrm{IrO}_{2}$ is the best electrocatalyst so far for OER. Moreover, it is difficult to get both acceptable OER and oxygen reduction reaction (ORR) activities with the same material. Therefore, a burgeoning effort by chemists is to develop inexpensive materials with high electrocatalytic activity and stability for OER or preferably for both OER and ORR, but it remains a daunting scientific challenge. In addition, electrolysis of water is generally preferred in alkaline medium over acidic medium because of the less expensive materials for construction and less susceptibility to corrosion ${ }^{11-13}$.

Transition metal oxides containing highly oxidized redox couples such as $\mathrm{Ir}^{4+/ 6+}, \mathrm{Ru}^{4+/ 8+}, \mathrm{Co}^{3+/ 4+}, \mathrm{Ni}^{3+/ 4+}$, $\mathrm{Mn}^{3+/ 4+}$ and $\mathrm{Fe}^{3+/ 4+}$ are known as active centres for OER. The electrochemical performance of oxides for OER follows the order, $\mathrm{IrO}_{2}>\mathrm{RuO}_{2}>\mathrm{Co}_{3} \mathrm{O}_{4}$ and $\mathrm{Ni}$-containing cobalt oxides $>\mathrm{Fe}, \mathrm{Pb}, \mathrm{Mn}$ containing oxides. Among the numerous low-cost oxides investigated, cobalt oxides are promising for both OER and ORR ${ }^{14-18}$ and have been largely studied as stable electrocatalysts for OER in highly alkaline solutions ${ }^{19}$. For example, spinel $\mathrm{NiCo}_{2} \mathrm{O}_{4}$ and $\mathrm{Co}_{3} \mathrm{O}_{4}$ have been found by several groups to show good efficiency and long-term performance, but they underperform relative to $\mathrm{IrO}_{2}$ (ref. 20). $\mathrm{Co}_{3} \mathrm{O}_{4}$ nanoparticles have also been anchored onto suitable conducting supports to prevent the agglomeration of nanoparticles and thereby increase the electrocatalytic activity. Recently, Liang et al. ${ }^{21}$ have used $\mathrm{Co}_{3} \mathrm{O}_{4}$ nanocrystals anchored onto graphene, while Frei and co-workers ${ }^{22}$ have developed efficient water oxidation electrocatalysts by supporting $\mathrm{MnO}_{\mathrm{x}}$ and
$\mathrm{Co}_{3} \mathrm{O}_{4}$ clusters on mesoporous silica scaffolds. Also, Kanan et al. $^{23}$ have used cobalt phosphate as an electrocatalyst for water oxidation.

With an aim to develop highly active electrocatalysts based on earth-abundant elements for both OER and ORR, we focus here on $\mathrm{LiCoO}_{2}$ as an electrocatalyst. $\mathrm{LiCoO}_{2}$ has been intensively studied as a cathode material for lithium-ion batteries ${ }^{24}$. $\mathrm{LiCoO}_{2}$ is known to exist in two forms as described below. The $\mathrm{LiCoO}_{2}$ sample synthesized at high temperatures $\left(\sim 800^{\circ} \mathrm{C}\right)$ has the $\alpha-\mathrm{NaFeO}_{2}$ structure (space group: $R \overline{3} m$ ) in which the $\mathrm{Li}^{+}$and $\mathrm{Co}^{3+}$ ions order on alternate $\{111\}$ planes of the rock salt structure due to the large size and charge differences between the $\mathrm{Li}^{+}$and $\mathrm{Co}^{3+}$ ions ${ }^{25}$. We designate this high-temperature form as $\mathrm{HT}-\mathrm{LiCoO}_{2}$. In contrast, the $\mathrm{LiCoO}_{2}$ sample synthesized at lower temperatures $\left(\sim 400^{\circ} \mathrm{C}\right)$ adopts a lithiated spinel structure $\left\{\mathrm{Li}_{2}\right\}_{16 \mathrm{c}}\left[\mathrm{Co}_{2}\right]_{16 \mathrm{~d}} \mathrm{O}_{4}$ in which the $\mathrm{Co}^{3+}$ ions occupy all the $16 \mathrm{~d}$ octahedral sites, while the $\mathrm{Li}^{+}$ions occupy all the $16 \mathrm{c}$ octahedral sites of the spinel framework (space group: $F d 3 m)^{26}$. We designate this low-temperature form as $\mathrm{LT}-\mathrm{LiCoO}_{2}$. In this paper, we compare the activities of $\mathrm{LT}-\mathrm{LiCoO}_{2}$ and $\mathrm{HT}-\mathrm{LiCoO}{ }_{2}$ having the same composition but different structures for OER in alkaline medium. LT-LiCoO 2 and $\mathrm{HT}-\mathrm{LiCoO}_{2}$, both consisting of $\mathrm{Co}^{3+}$ ions, offer a unique platform to explore the structureactivity relationship for OER. While LT- $\mathrm{LiCoO}_{2}$ consists of the cubane-like cubic $\mathrm{Co}_{4} \mathrm{O}_{4}$ units, HT- $\mathrm{LiCoO}_{2}$ consists of $\mathrm{LiCo}_{3} \mathrm{O}_{4}$ units. Also, the changes in the surface structure of $\mathrm{LT}-\mathrm{LiCoO}_{2}$ and its OER activity as a function of the firing time and temperature around $400{ }^{\circ} \mathrm{C}$ are presented. We also compare the OER and ORR activities of chemically delithiated LT- $\mathrm{Li}_{1-\mathrm{x}} \mathrm{CoO}_{2}$ as a function of lithium content $(0 \leq x \leq 0.5)$ and the oxidation state of Co with an aim to utilize it as a bifunctional electrocatalyst for OER and ORR.

\section{Results}

Bulk and surface structures. Both the atomic and electronic structures, particularly on the surface under the electrochemical operating conditions, play a critical role in imparting the electrocatalytic activity for OER and ORR. Figure 1a shows the X-ray diffraction patterns of LT- $\mathrm{LiCoO}_{2}, \mathrm{HT}-\mathrm{LiCoO}_{2}$ and $\mathrm{Co}_{3} \mathrm{O}_{4}$. While the $\mathrm{LT}-\mathrm{LiCoO}_{2}$ synthesized at $400{ }^{\circ} \mathrm{C}$ shows a single reflection around $2 \theta \approx 63^{\circ}$ corresponding to the $\{440\}$ plane of the cubic lithiated spinel $(F d 3 m)$, it splits into the (108) and (110) reflections of the layered $\mathrm{HT}-\mathrm{LiCoO}_{2}$ structure $(R \overline{3} \mathrm{~m})$ on heating to $800^{\circ} \mathrm{C}^{27-30}$. Also, the (220) reflection present in $\mathrm{Co}_{3} \mathrm{O}_{4}$ is absent in $\mathrm{LT}-\mathrm{LiCoO}_{2}$ due to the absence of ions with high scattering
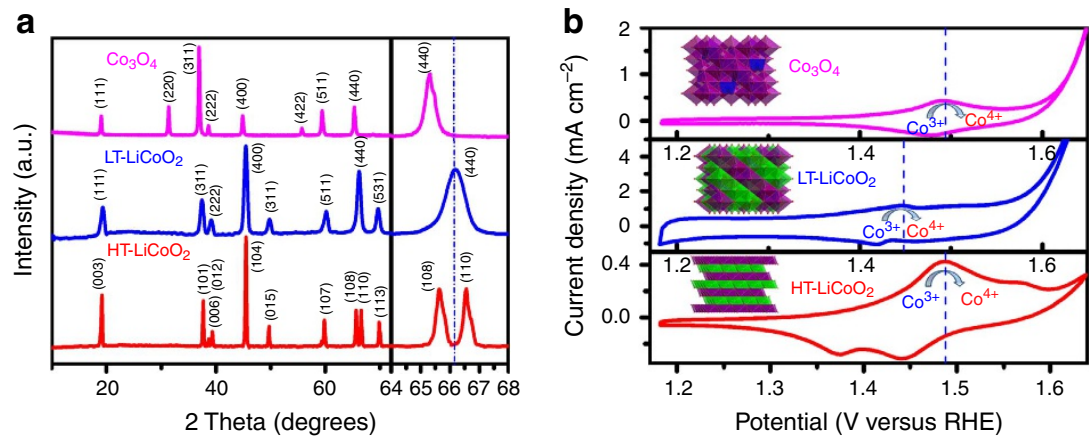

Figure 1 | X-ray diffraction patterns and electrochemical behaviour of electrocatalysts. (a) X-ray diffraction patterns of $\mathrm{Co}_{3} \mathrm{O}_{4}, \mathrm{LT}^{-} \mathrm{LiCoO} \mathrm{O}_{2}$ and $\mathrm{HT}-\mathrm{LiCoO}_{2}$, illustrating the splitting of the (440) reflection in the cubic spinel $\mathrm{LT}_{\mathrm{LiCoO}}$ into (108) and (110) reflections in the rhombohedral-layered $\mathrm{LT}-\mathrm{LiCoO} 2$ as shown in the expanded region of $2 \theta=64-68^{\circ}$. (b) Cyclic voltammograms of $\mathrm{Co}_{3} \mathrm{O}_{4}, \mathrm{LT}^{-} \mathrm{LiCoO} 2$ and $\mathrm{HT}$ - $\mathrm{LiCoO} 2$ in $0.1 \mathrm{M} \mathrm{KOH}$ at scan rate of $5 \mathrm{mVs}^{-1}$. The purple, blue and green colours in the structures shown in the insets of $\mathbf{b}$ refer, respectively, to the polyhedra of $\mathrm{Co}^{3+}, \mathrm{Co}^{2+}$ and $\mathrm{Li}^{+}$ions. 
power in the $8 \mathrm{a}$ tetrahedral sites of the spinel lattice in LT$\mathrm{LiCoO}_{2} \cdot \mathrm{Co}_{3} \mathrm{O}_{4}$ has the cubic spinel structure with a cation distribution of $\left(\mathrm{Co}^{2+}\right)_{8 \mathrm{a}}\left[\mathrm{Co}_{2}^{3+}\right]_{16 \mathrm{~d}} \mathrm{O}_{4}$ in which all the $\mathrm{Co}^{3+}$ ions occupy the $16 \mathrm{~d}$ octahedral sites, while all $\mathrm{Co}^{2+}$ ions occupy the 8 a tetrahedral sites. Supplementary Fig. 1 shows the Rietveld refinement of the X-ray diffraction data of $\mathrm{LT}-\mathrm{LiCoO}_{2}$ and HT$\mathrm{LiCoO}_{2}$ along with $\mathrm{Co}_{3} \mathrm{O}_{4}$. The observed and calculated patterns match well with each other, validating the cubic lithiated spinel structure of $\mathrm{LT}-\mathrm{LiCoO}_{2}$. The structural parameters obtained from the Rietveld refinement are given in Supplementary Table 1.

Figure 2 shows the aberration-corrected high angular annular dark-field scanning transmission electron microscopy (STEM) images of the three samples, viewed down the $[01 \overline{1}]$ zone axis. The atomic arrangement in the $\mathrm{Co}_{3} \mathrm{O}_{4}$ particle matches that expected for the spinel lattice with the space group $\mathrm{Fd} \overline{3} \mathrm{~m}$, where the $\mathrm{Co}^{3+}$ ions occupy the octahedral sites and $\mathrm{Co}^{2+}$ ions occupy the tetrahedral sites (Fig. 2c,d). The particle maintains this structure all the way to the surface on both the $\{001\}$ and $\{111\}$ planes (Fig. 2a,b, respectively). As a comparison, the surfaces of the $\{001\}$ and the $\{111\}$ planes in $\mathrm{HT}-\mathrm{LiCoO}_{2}$ are shown in Fig. 2e,f. The overall structure matches that of a trigonal lattice with the space group $R \overline{3} m$ (Fig. $2 \mathrm{~g}, \mathrm{~h}$ ). For ease of comparison, we will use the cubic system, which is the most basic structure of $\mathrm{HT}-\mathrm{LiCoO}_{2}$, for the notation of the planes in both the figures and the discussion of $\mathrm{HT}-\mathrm{LiCoO}_{2}$. The bulk structure of $\mathrm{HT}-\mathrm{LiCoO} \mathrm{C}_{2}$ is maintained all the way to the surface on the $\{111\}$ planes (Fig. 2f), but shows some variation for a few layer of the $\{001\}$ surface (Fig. 2e). At this surface, there are some bright atomic columns of Co that appear in the Li layers, suggesting that some Co might have moved into the lithium layer at the $\{001\}$ cubic surface. The bulk structure of $\mathrm{LT}-\mathrm{LiCoO}_{2}$ is shown in Fig. $2 \mathrm{i}$, and it indicates that the structure corresponds to a spinel lattice with the space group $F d \overline{3} m$ and Co and Li occupying, respectively, all the 16d and $16 \mathrm{c}$ octahedral sites (Fig. 2j,k). The structure of the $\{001\}$ planes is maintained all the way to the surface (Fig. 2i). The structure of the $\{111\}$ planes at the surface, however, is modified under certain synthesis conditions (Fig. 3). For example, for a firing temperature of $370{ }^{\circ} \mathrm{C}$ for 7 days, the spinel structure is maintained all the way to the $\{111\}$ surface (Fig. 3a). For firing temperatures of 385 and $400{ }^{\circ} \mathrm{C}$ for 7 days, however, a few atomic layers of the $\{111\}$ surface planes have transformed to the layered $\mathrm{HT}-\mathrm{LiCoO}_{2}$ (Fig. 3b,c). In contrast, for a firing temperature of
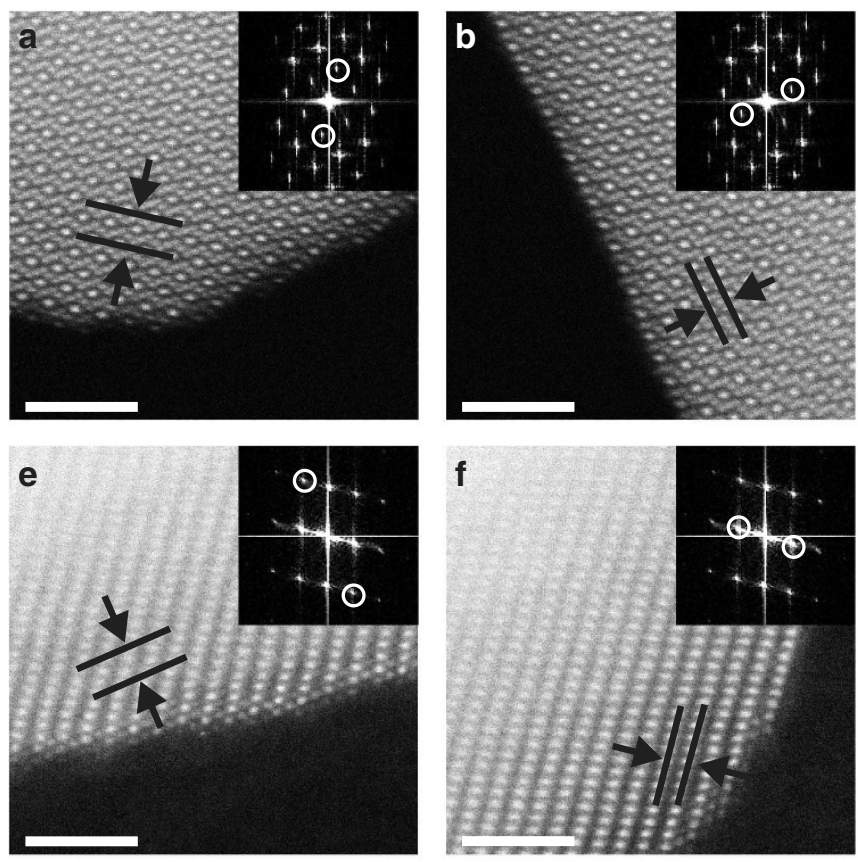
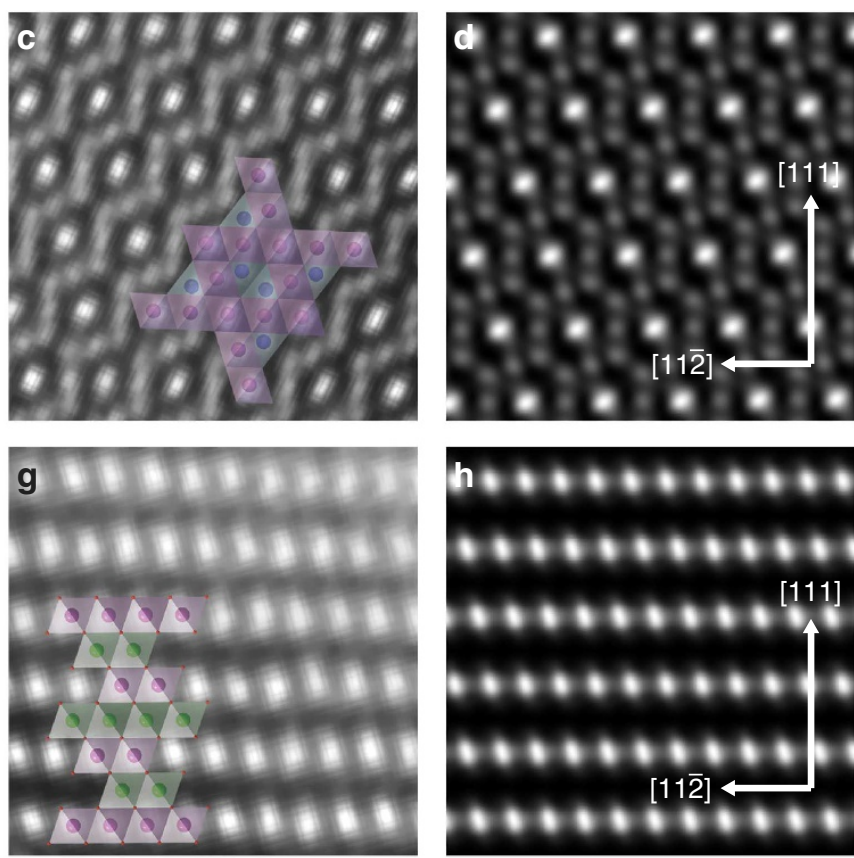

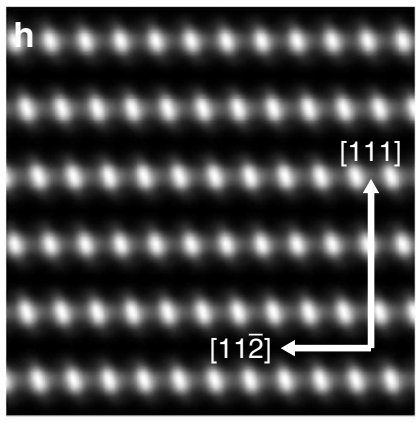

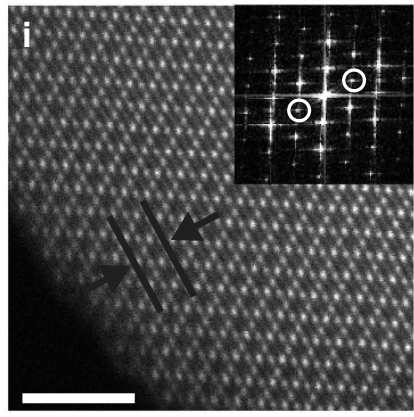
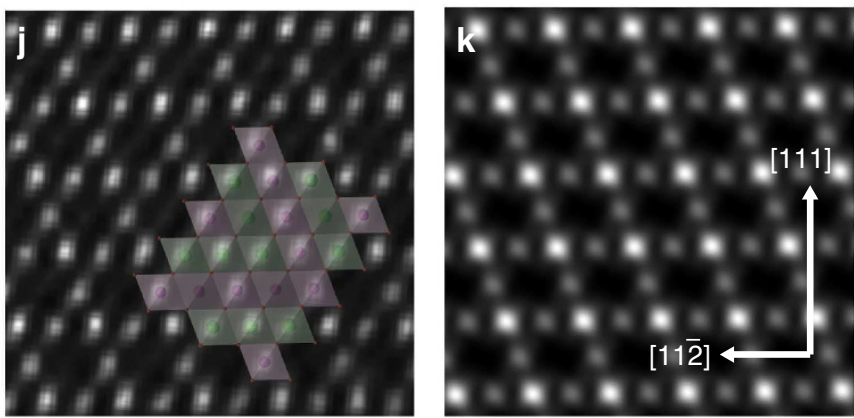

Figure 2 | Aberration-corrected HAADF-STEM images of electrocatalyts. HAADF-STEM images of (a-d) $\mathrm{Co}_{3} \mathrm{O}_{4},(\mathbf{e}-\mathbf{h}) \mathrm{HT}_{\mathrm{L}} \mathrm{LiCoO} 2$ and $(\mathbf{i}-\mathbf{k}) \mathrm{LT}_{\mathrm{C}} \mathrm{LiCoO} 2$ viewed down the [011] zone axis, showing the surface structure at the $(\mathbf{a}, \mathbf{e}, \mathbf{i})\{001\}$ plane and $(\mathbf{b}, \mathbf{f})\{111\}$ plane. These surface planes are indicated by black bars and arrows in the image and circles in the inset fast Fourier transform's (FFT's). The unit cells for each composition with octahedral and tetrahedral arrangements are overlaid on higher magnification images that have been deconvoluted to reduce noise in $(\mathbf{c}, \mathbf{g}, \mathbf{j}){ }^{44}$. The blue, purple and green atoms refer, respectively, to $\mathrm{Co}^{2+}, \mathrm{Co}^{3+}$ and $\mathrm{Li}^{+}$. The simulated STEM images are shown in (d,h,k). To facilitate a comparison of the three materials, the deconvoluted and simulated images have been rotated relative to the STEM images, so that all the $\{111\}$ planes lie on the horizontal axis. Scale bar, $2 \mathrm{~nm}$. 

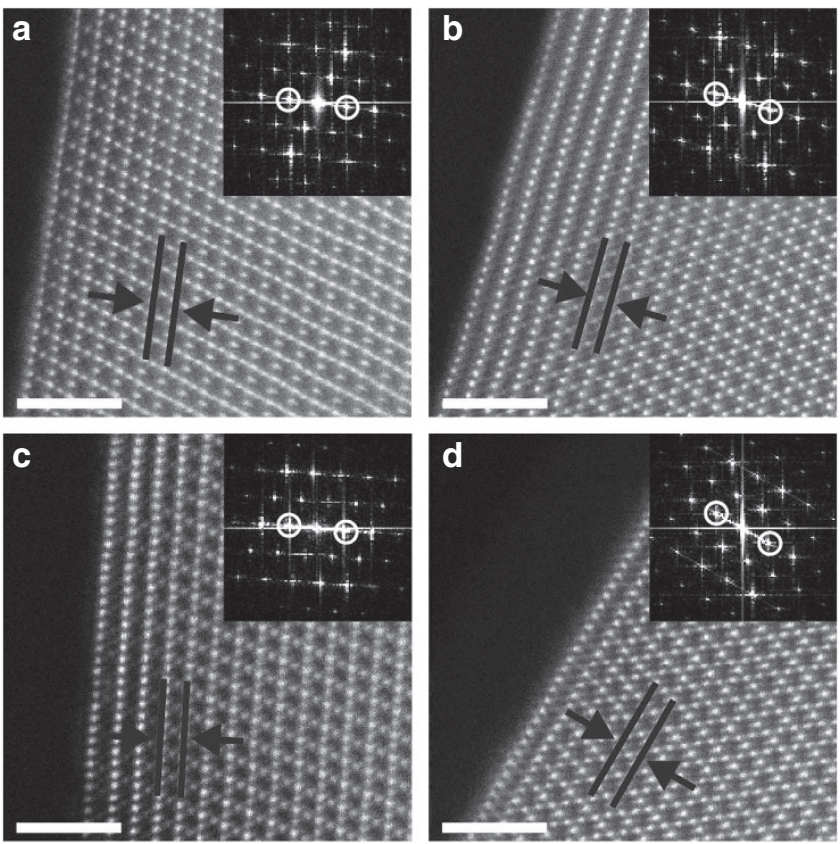

Figure 3 | Aberration-corrected HAADF-STEM images of LT-LiCoO 2 . HAADF-STEM images of $\mathrm{LT}-\mathrm{LiCoO}_{2}$ viewed down the [011] zone axis showing the atomic structure of the $\{111\}$ planes at the surface for samples prepared at (a) $370^{\circ} \mathrm{C}$ for 7 days, (b) $385^{\circ} \mathrm{C}$ for 7 days, (c) $400^{\circ} \mathrm{C}$ for 7 days and (d) $400^{\circ} \mathrm{C}$ for 4 days. These surface planes are indicated by black bars and arrows in the image and circles in the inset fast Fourier transform 's (FFT's). The scale bars are $2 \mathrm{~nm}$.

$400{ }^{\circ} \mathrm{C}$ for 4 days, only the first layer has transformed to the layered $\mathrm{HT}-\mathrm{LiCoO}_{2}$ phase (Fig. 3d).

Electrochemical behaviour. Cyclic voltammograms (CVs) recorded for all the three electrocatalysts under the same experimental conditions at a scan rate of $5 \mathrm{mV} \mathrm{s}^{-1}$ are presented in Fig. 1b. The enlarged CVs and the CVs recorded for an extended number of cycles are shown in Supplementary Fig. 2. The $\mathrm{CV}$ of $\mathrm{Co}_{3} \mathrm{O}_{4}$ is characterized by a single anodic peak before the OER and a single cathodic peak, which have been attributed to the quasi-reversible redox couple $\left(\mathrm{CoO}_{2} / \mathrm{CoOOH}\right)$ occurring on $\mathrm{Co}_{3} \mathrm{O}_{4}$ surface ${ }^{15,31}$. The $\mathrm{CV}$ of $\mathrm{HT}-\mathrm{LiCoO}_{2}$ differs considerably from that of $\mathrm{Co}_{3} \mathrm{O}_{4}$. HT- $\mathrm{LiCoO}_{2}$ shows two peaks during the anodic process and two peaks during the cathodic process, and the redox peaks become more pronounced during extended CV cycling (Supplementary Fig. 2b). Unlike in $\mathrm{Co}_{3} \mathrm{O}_{4}$, the $\mathrm{Co}^{3+/ 4}+$ oxidation/reduction in $\mathrm{HT}-\mathrm{LiCoO}_{2}$ is accompanied by lithium extraction/insertion. Also, $\mathrm{HT}-\mathrm{LiCoO}_{2}$ is known to insert protons into the lattice during chemical delithiation (with $\mathrm{NO}_{2} \mathrm{BF}_{4}$ even in acetonitrile medium) for $\mathrm{x}>0.5$ in HT$\mathrm{Li}_{1-\mathrm{x}} \mathrm{CoO}_{2}$ and transform from the O3-layered structure to the P3-layered structure 32,33 . While the $\mathrm{Li}^{+}$ions are in octahedral sites in the $\mathrm{O} 3$ structure, the $\mathrm{Li}^{+} / \mathrm{H}^{+}$ions are in prismatic sites in the $\mathrm{P} 3$ structure. Thus, the occurrence of two peaks during the anodic or cathodic process is due to the extraction/insertion of $\mathrm{Li}^{+} / \mathrm{H}^{+}$into two different crystallographic sites. It should be noted that the second anodic peak is weak and it becomes invisible at higher scan rates (for example, $20 \mathrm{mV} \mathrm{s}^{-1}$ ), possibly due to the slow kinetics associated with the extraction/insertion of $\mathrm{Li}^{+} / \mathrm{H}^{+}$from/into the prismatic sites. LT- $\mathrm{LiCoO}_{2}$ also shows two anodic peaks (Fig. $1 \mathrm{~b}$ and Supplementary Fig. 2), but the second peak is much weaker even at a slow scan rate of $5 \mathrm{mV} \mathrm{s}^{-1}$.
This is because the lithium diffusion rate is much slower in LT-LiCoO 2 , which has a lithiated spinel structure formed at low temperatures, possibly with defects, compared with that in $\mathrm{HT}-\mathrm{LiCoO}_{2}$ that has a well-formed, well-ordered layered structure ${ }^{30,34}$. In addition, $\mathrm{LT}-\mathrm{LiCoO}_{2}$ may also undergo structural transformations at deep lithium extraction, involving possibly proton insertion, due to the instability at high $\mathrm{Co}^{4+}$ contents. Thus, the occurrence of two peaks is due the extraction/ insertion of $\mathrm{Li}^{+} / \mathrm{H}^{+}$from/into two different lattice sites. It is clear that the anodic peak corresponding to lithium extraction is sensitive to diffusion coefficient and the $\mathrm{CV}$ scan rate ${ }^{35}$. Furthermore, the anodic peak in $\mathrm{LT}-\mathrm{LiCoO}_{2}$ occurs at a lower potential $(1.43 \mathrm{~V})$ than that in $\mathrm{HT}-\mathrm{LiCoO}_{2}(1.49 \mathrm{~V})$, despite the same composition and oxidation state of $\mathrm{Co}$, reflecting the influence of crystal structure (spinel-like versus layered). Supplementary Table 2 gives the potential and redox couples for various electrocatalysts.

Nocera's group ${ }^{36}$ has pointed out that the structurally strained, unstable $\mathrm{Co}^{4+}$ species on the surface acts as an intermediate species for OER. They have also demonstrated $\mathrm{Co}^{4+}$ active site formation by EPR during the OER conditions. Rasiyah et al. ${ }^{37}$ have shown a relationship between the onset potential for OER and the potential of the lower oxide/higher oxide couple. For example, the redox couples of $\mathrm{IrO}_{2}$ and $\mathrm{RuO}_{2}$ occurring at lower potentials results in lower OER onset potentials for both compositions ${ }^{37}$. Thus, the occurrence of the $\mathrm{Co}^{3+} / \mathrm{Co}^{4+}$ redox couple peak at a lower potential in $\mathrm{LT}-\mathrm{LiCoO}_{2}$ leads to lower OER onset potential compared with those of $\mathrm{HT}-\mathrm{LiCoO}_{2}$ and $\mathrm{Co}_{3} \mathrm{O}_{4}$ (Supplementary Table 2).

The electrocatalytic activities of $\mathrm{Co}_{3} \mathrm{O}_{4}, \mathrm{LT}-\mathrm{LiCoO}_{2}, \mathrm{HT}-\mathrm{LiCoO}_{2}$ and the conventional $\mathrm{IrO}_{2}$ samples for OER were studied by linear sweep voltammetry in oxygen-saturated $0.1 \mathrm{M} \mathrm{KOH}$ solution at a scan rate of $20 \mathrm{mVs}^{-1}$. The mass normalized OER activities (Fig. 4a) of the samples increase in the order: $\mathrm{HT}-\mathrm{LiCoO}_{2}<$ $\mathrm{Co}_{3} \mathrm{O}_{4}<\mathrm{IrO}_{2}<\mathrm{LT}-\mathrm{LiCoO}_{2}$. Among the electrocatalysts studied, the layered $\mathrm{HT}-\mathrm{LiCoO}_{2}$ sample exhibits the lowest OER activity, close to that of the well-studied $\mathrm{Co}_{3} \mathrm{O}_{4}$, while the LT-LiCoO sample (prepared at $400{ }^{\circ} \mathrm{C}$ for 7 days) exhibits the highest OER activity that is even slightly better than that of the well-known $\mathrm{IrO}_{2}$ electrocatalyst. However, $\mathrm{IrO}_{2}$ shows a lower OER onset potential compared with LT-LiCoO 2 . Also, LT- $\mathrm{LiCoO}_{2}$ exhibits much higher OER activity than the best-studied perovskite oxide $\mathrm{Ba}_{0.5} \mathrm{Sr}_{0.5} \mathrm{Co}_{0.8} \mathrm{Fe}_{0.2} \mathrm{O}_{3-\delta}$ (refs 2,38) (Supplementary Table 3). Linear sweep voltammograms cycles of $\mathrm{LT}^{-\mathrm{LiCoO}_{2}}$ in $0.1 \mathrm{M}$ $\mathrm{KOH}$ at $\mathrm{pH}=13$ are shown in Supplementary Fig. 3. Interestingly, the OER activity is found to increase gradually, approach a stable value after 100 cycles, and then decrease slowly after 200 cycles. Anodic linear scanning voltammograms for OER on the LT$\mathrm{LiCoO}_{2}$ electrodes at different sweep rates are shown in Supplementary Fig. 4.The current density increases with increasing sweeping rate. The high OER activity of LT- $\mathrm{LiCoO}_{2}$ is consistent with the high activity observed recently for the photocatalytic oxidation of water ${ }^{39}$. To understand the OER activities further, the Tafel plot analysis is shown in Supplementary Fig. 5. The Tafel slope observed for $\mathrm{Co}_{3} \mathrm{O}_{4}\left(67 \mathrm{mV} \mathrm{dec}^{-1}\right)$ is in good agreement with those reported for $\mathrm{Co}_{3} \mathrm{O}_{4}$ nanocrystals on a graphene support $^{31}$. The $\mathrm{LT}-\mathrm{LiCoO}_{2}$ and $\mathrm{LT}-\mathrm{Li}_{0.5} \mathrm{CoO}_{2}$ samples exhibit smaller Tafel slopes of, respectively, 52 and $60 \mathrm{mV} \mathrm{dec}^{-1}$ than $\mathrm{Co}_{3} \mathrm{O}_{4}$ and $\mathrm{HT}-\mathrm{LiCoO}$, which is consistent with the reported values of $63 \mathrm{mV} \mathrm{dec}^{-1}$ for lithium-doped $\mathrm{Co}_{3} \mathrm{O}_{4}$ in alkaline electrolytes ${ }^{37}$. Also, LT-LiCoO${ }_{2}$ and $\mathrm{LT}-\mathrm{Li}_{0.5} \mathrm{CoO}_{2}$ exhibit higher exchange current densities than $\mathrm{Co}_{3} \mathrm{O}_{4}$ and $\mathrm{HT}-\mathrm{LiCoO}_{2}$. The higher exchange current density and smaller Tafel slope of LT-LiCoO 2 attest to its good electrocatalytic activity for OER.

The large difference between the OER performances of $\mathrm{LT}-\mathrm{LiCoO}_{2}$ and $\mathrm{HT}-\mathrm{LiCoO}_{2}$ again reflects the importance of 
structural features for OER, for example, $\mathrm{Co}_{4} \mathrm{O}_{4}$ cubane units in LT- $\mathrm{LiCoO}_{2}$ versus $\mathrm{LiCo}_{3} \mathrm{O}_{4}$ units in $\mathrm{HT}-\mathrm{LiCoO}_{2}$. Finally, despite the same spinel framework, the spinel $\mathrm{Co}_{3} \mathrm{O}_{4}$ sample shows much lower activity (similar to that of layered LT-LiCoO ${ }_{2}$ ) than the lithiated spinel LT- $\mathrm{LiCoO}_{2}$ sample. This difference may be due to the presence of $\mathrm{Co}^{2+}$ ions in the $8 \mathrm{a}$ tetrahedral sites of $\mathrm{Co}_{3} \mathrm{O}_{4}$ and the difficulty of oxidizing the tetrahedral-site $\mathrm{Co}^{2+}$ ions before oxidizing the octahedral-site $\mathrm{Co}^{3+}$ ions to $\mathrm{Co}^{4+}$. This again reflects the importance of surface atomic arrangements and electronic structures for OER.

Figure $4 \mathrm{~b}$ compares the OER activities of the LT- $\mathrm{LiCoO}_{2}$ samples prepared under various conditions. As seen, the sample fired at $400{ }^{\circ} \mathrm{C}$ for 7 days shows the highest OER activity, while the sample fired at $370^{\circ} \mathrm{C}$ for 7 days shows the lowest OER activity, but all of them exhibit higher activity than $\mathrm{HT}-\mathrm{LiCoO}_{2}$. The lowest activity of the sample fired at $370{ }^{\circ} \mathrm{C}$ for 7 days could be due to the incomplete solid state-reaction and the unreacted raw materials on the surface. For a given firing temperature of $400^{\circ} \mathrm{C}$, the OER activity increases with increasing firing time from 4-5 to 7 days. Similarly, for a given firing time of 7 days, the OER activity increases with increasing firing temperature from $370-385$ to $400{ }^{\circ} \mathrm{C}$. These observations reflect the importance of completing the solid-state reaction and realizing the optimum surface structures favourable for OER. It is possible that the presence of a few layers of layered $\mathrm{HT}-\mathrm{LiCoO}_{2}$ on the surface of LT- $\mathrm{LiCoO}_{2}$ and the consequent surface strains arising from slight lattice mismatch between the two structures may play a role in maximizing the OER activity; future in-depth investigation could shed more light on this.

The long-term stability of the electrocatalysts is a critical factor for them to be employed in practical devices. Accordingly, the durability of the electrocatalysts for OER at an applied potential of $1.7 \mathrm{~V}$ at $\mathrm{pH}=13$ and 7 was evaluated by chronoamperometry (Fig. $4 \mathrm{c}, \mathrm{d})$. The $\mathrm{Co}_{3} \mathrm{O}_{4}$ sample is stable both in alkaline $(\mathrm{pH}=13)$ and neutral $(\mathrm{pH}=7)$ media as seen in Fig. $4 \mathrm{c}$,d. Interestingly, while the layered $\mathrm{HT}-\mathrm{LiCoO}_{2}$ shows a decrease in OER activity with time in alkaline medium (Fig. 4c) and even in neutral medium (Fig. 4d), the lithiated spinel LT- $\mathrm{LiCoO}_{2}$ is stable in both neutral and alkaline $(\mathrm{pH}=13)$ media with time $(6 \mathrm{~h})$ as seen in Fig. 4c,d. Clearly, in addition to the higher OER activity, the spinel LT- $\mathrm{LiCoO}_{2}$ offers stability advantages compared with the layered $\mathrm{HT}-\mathrm{LiCoO}_{2}$, in spite of a slightly larger surface area for LT- $\mathrm{LiCoO}_{2}\left(9.6 \mathrm{~m}^{2} \mathrm{~g}^{-1}\right)$ compared with that for HT-LiCoO $\left(1.7 \mathrm{~m}^{2} \mathrm{~g}^{-1}\right)$; the surface area of $\mathrm{LT}-\mathrm{LiCoO}_{2}$ was similar to that of $\mathrm{Co}_{3} \mathrm{O}_{4}\left(9.4 \mathrm{~m}^{2} \mathrm{~g}^{-1}\right)$. The stability differences again reflect the importance of atomic arrangements for stable OER activity.

Chemically delithiated LT- $\mathrm{Li}_{1-\mathrm{x}} \mathrm{CoO}_{2}$. For an electrocatalyst to be employed in rechargeable metal-air batteries, it should display both acceptable OER and ORR activities. Accordingly, the ORR activity of LT- $\mathrm{LiCoO}_{2}$ was evaluated with a rotating-disk electrode (RDE) in $\mathrm{O}_{2}$-saturated $0.1 \mathrm{M} \mathrm{KOH}$ electrolyte. As seen in Fig. 5a, LT- $\mathrm{LiCoO}_{2}$ shows poor ORR activity, which is worse than that of $\mathrm{Co}_{3} \mathrm{O}_{4}$. Considering that samples with mixed-valent $\mathrm{Co}^{3+14+}$ are known to generally exhibit high ORR activities ${ }^{40}$, lithium was extracted chemically from LT- $\mathrm{LiCoO}_{2}$ with the oxidizer $\mathrm{NO}_{2} \mathrm{BF}_{4}$ in acetonitrile medium ${ }^{33,41}$ to give $\mathrm{LT}-\mathrm{Li}_{1-\mathrm{x}} \mathrm{CoO}_{2}(0 \leq \mathrm{x} \leq 0.5)$ with mixedvalent $\mathrm{Co}^{3+14+}$. Interestingly, the ORR activity of the delithiated LT- $\mathrm{Li}_{1-\mathrm{x}} \mathrm{CoO}_{2}$ samples increases with decreasing lithium content and the LT- $\mathrm{Li}_{0.5} \mathrm{CoO}_{2}$ sample exhibits the highest ORR activity in Fig. 5a. Figure $5 \mathrm{~b}$ displays the OER activities of the delithiated LT- $\mathrm{Li}_{1-\mathrm{x}} \mathrm{CoO}_{2}$ samples, and the OER activity decreases slightly
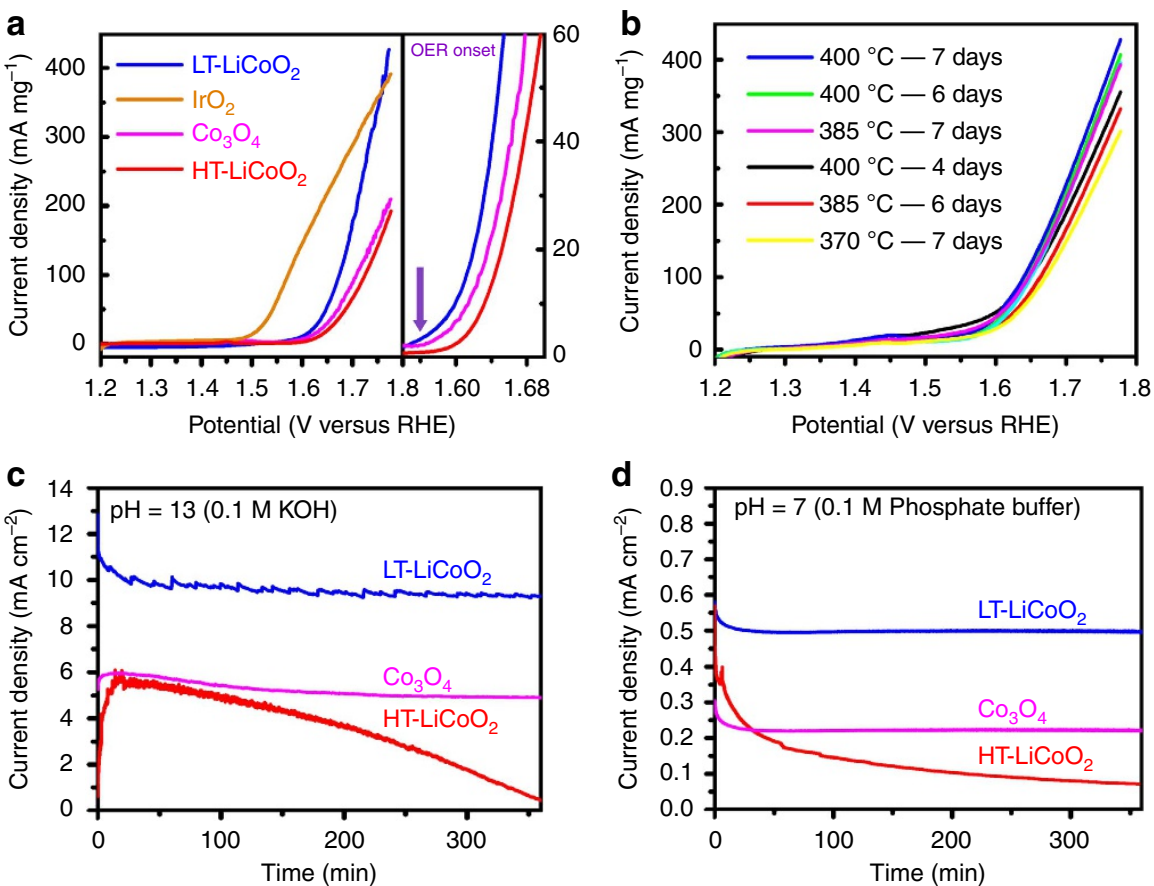

Figure 4 | OER Performances of the electrocatalysts. (a) Linear sweep voltammograms of $\mathrm{LT}$ - $\mathrm{LiCOO}_{2}, \mathrm{IrO}_{2}, \mathrm{CO}_{3} \mathrm{O}_{4}$ and $\mathrm{HT}$ - LiCoO 2 at a scan rate of $20 \mathrm{mVs}^{-1}$ at 1,600 r.p.m. in $0.1 \mathrm{M} \mathrm{KOH}$ at pH=13, with an expanded region shown on the right. (b) Effect of firing temperature and time on the OER

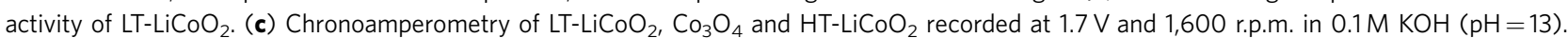

(d) Chronoamperometry of $\mathrm{LT}_{-} \mathrm{LiCoO}_{2}, \mathrm{Co}_{3} \mathrm{O}_{4}$ and $\mathrm{HT}$ - $\mathrm{LiCoO}_{2}$ recorded at $1.7 \mathrm{~V}$ and 1,600 r.p.m. in $0.1 \mathrm{M}$ phosphate buffer solution ( $\mathrm{pH}=7$ ). Some fluctuations observed in the data points at high $\mathrm{pH}$ compared with the neutral $\mathrm{pH}$ arise from the formation of bubbles on the surface of the electrode. The glassy carbon RDE electrodes were held under rotation at 1,600 r.p.m. during the course of the experiment in order to effectively remove the bubbles formed during the OER. All activities are IR-corrected and normalized to the mass activity. 


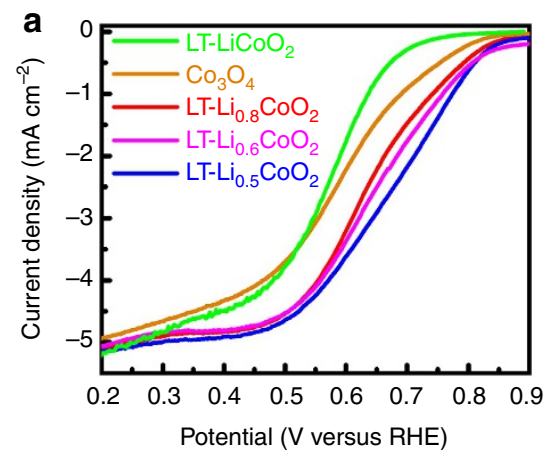

C

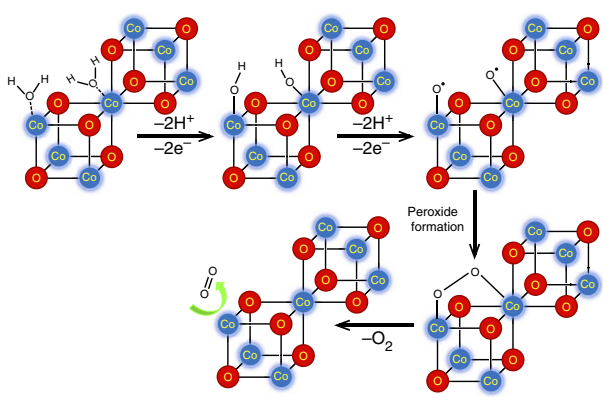

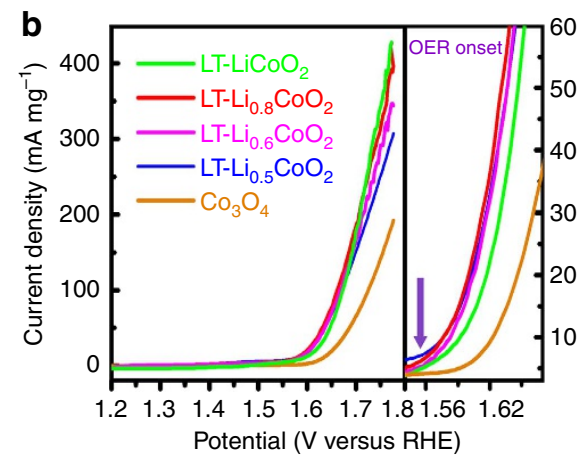

d

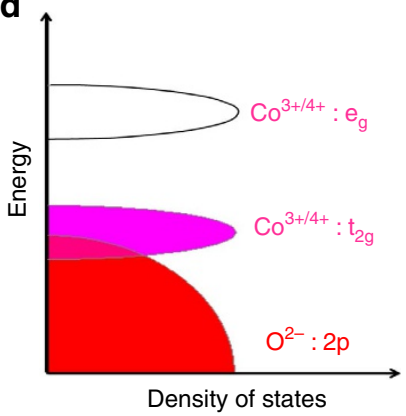

Figure 5 | Electrochemical performances of delithiated $\mathbf{L T}-\mathrm{Li}_{\mathbf{1}_{-\mathbf{x}}} \mathbf{C o O}_{\mathbf{2}}$ electrocatalysts. (a) ORR activities of $\mathrm{LT}-\mathrm{Li}_{1-x} \mathrm{CoO}_{2}$ for $0 \leq x \leq 0.5$ in comparison

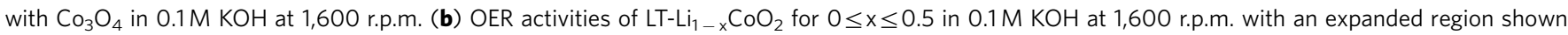

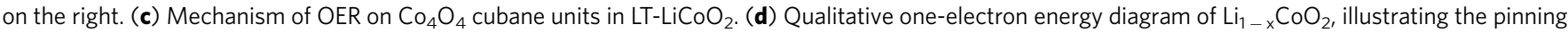
of the $\mathrm{Co}^{3+/ 4+}: 3 \mathrm{~d}$ energy with the top of the $\mathrm{O}^{2-}: 2 \mathrm{p}$ band.

with decreasing lithium content. Nevertheless, the LT- $\mathrm{Li}_{0.5} \mathrm{CoO}_{2}$ sample exhibits 1.5 times higher OER activity than the $\mathrm{Co}_{3} \mathrm{O}_{4}$ sample. However, the delithiated LT- $\mathrm{Li}_{0.5} \mathrm{CoO}_{2}$ sample exhibits slightly lower stability than $\mathrm{LT}-\mathrm{LiCoO}_{2}$ at $\mathrm{pH}=13$ (Supplementary Fig. 6a). The ambient-temperature chemical delithiation offers an approach to vary the $d$-electron count on the transition-metal ion and explore its influence on ORR and OER activities. In addition, the LT- $\mathrm{LiCoO}_{2}$ sample shows good long-term stability for $20 \mathrm{~h}$ (Supplementary Fig. 6a), better than the highest reported for perovskite $\mathrm{Ba}_{0.5} \mathrm{Sr}_{0.5} \mathrm{Co}_{0.8} \mathrm{Fe}_{0.2} \mathrm{O}_{3-\delta}$ (refs $2,38)$. Thus, the chemically delithiated spinel-type $\mathrm{LT}-\mathrm{Li}_{0.5} \mathrm{CoO}_{2}$ exhibits a combination of high ORR and OER activities with good stability, demonstrating it to be an excellent bifunctional electrocatalyst.

\section{Discussion}

We have successfully demonstrated that the non-noble metal LT$\mathrm{LiCoO}_{2}$ synthesized at $400^{\circ} \mathrm{C}$ exhibits superior OER activity, even slightly better than that of $\mathrm{IrO}_{2}$. This is the highest mass activity reported to date for a non-noble-metal electrocatalyst or a noblemetal catalyst. For a material to have good OER activity, it should have high electronic conductivity and great affinity for adsorbed $\mathrm{OH}^{-}$intermediates. For example, $\mathrm{IrO}_{2}$ is known to be the most active and stable electrocatalyst for OER in acid and alkaline media due to its interesting electronic structure and metallic conductivity. The OER reaction with $\mathrm{IrO}_{2}$ involves an oxidation of low-spin $\operatorname{Ir}^{4+}: 5 \mathrm{~d}^{5}\left(\mathrm{t}_{2 \mathrm{~g}}^{5} \mathrm{e}_{\mathrm{g}}^{0}\right)$ ions to $\mathrm{Ir}^{6+}: 5 \mathrm{~d}^{5}\left(\mathrm{t}_{2 \mathrm{~g}}^{3} \mathrm{e}_{\mathrm{g}}^{0}\right)$ on the surface. The decrease in crystal field stabilization energy (CFSE) during this process has been suggested to make $\operatorname{Ir}^{6+}$ unstable $^{37}$, favouring a facile OER reaction. Similarly, the high OER activity of $\mathrm{LT}-\mathrm{LiCoO}_{2}$ could be related to (i) the decrease in CFSE during the oxidation of low-spin $\mathrm{Co}^{3+}: 3 \mathrm{~d}^{6}\left(\mathrm{t}_{2 \mathrm{~g}}^{6} \mathrm{e}_{\mathrm{g}}^{0}\right)$ ions to $\mathrm{Co}^{4+}: 3 \mathrm{~d}^{5}\left(\mathrm{t}_{2 \mathrm{~g}}^{5} \mathrm{e}_{\mathrm{g}}^{0}\right)$ on the surface or the formation of intermediate-spin $\mathrm{Co}^{3+}\left(\mathrm{t}_{2 \mathrm{~g}}^{5} \mathrm{e}_{\mathrm{g}}^{1}\right)$ ions on the surface under the OER conditions in contact with the electrolyte and (ii) the high (possibly metallic) conductivity arising from the partially filled $t_{2 g}$ orbitals of $\mathrm{Co}^{4+}$ or intermediate-spin $\mathrm{Co}^{3+}$ ions across the shared octahedral edges of the spinel framework.

In addition, the high OER activity of $\mathrm{LT}-\mathrm{LiCoO}_{2}$ may be related to the $\mathrm{Co}_{4} \mathrm{O}_{4}$ cubane-like structure similar to that found in natures' water oxidation catalyst $\mathrm{CaMn}_{4} \mathrm{O}_{\mathrm{x}}{ }^{4-8}$ as illustrated in Fig. $5 \mathrm{c}$ and the pinning of the $\mathrm{Co}^{3+/ 4+}: 3 \mathrm{~d}$ energy with the top of the $\mathrm{O}^{2-}: 2 \mathrm{p}$ band as shown in Fig. 5d. Direct coupling on adjacent $\mathrm{Co}^{3+14+}$ ions across a large number of cubic faces can facilitate the formation of $\mathrm{O}-\mathrm{O}$ bonds easily as illustrated in Fig. 5c, leading to an easier release of oxygen ${ }^{42,43}$. Similar mechanisms could occur with other spinel OER electrocatalysts as well, but the pinning of the $\mathrm{Co}^{3+/ 4+}: 3 \mathrm{~d}$ energy with the top of the $\mathrm{O}^{2-}: 2 \mathrm{p}$ band may play a key role. In contrast, the presence of $\mathrm{LiCo}_{3} \mathrm{O}_{4}$ units rather than $\mathrm{Co}_{4} \mathrm{O}_{4}$ units in $\mathrm{HT}-\mathrm{LiCoO}_{2}$ diminishes such coupling across the cubic faces, resulting in lower OER activity.

Furthermore, the surface atomic arrangement of $\mathrm{LT}-\mathrm{LiCoO}{ }_{2}$ is sensitive to the firing temperature (around $400{ }^{\circ} \mathrm{C}$ ) and time. The transformation of surface layers from a spinel-type arrangement to a layer-type arrangement with increasing firing temperature or time reveals that the spinel $\mathrm{LT}-\mathrm{LiCoO}_{2}$ is metastable (kinetically stabilized due to the lack of adequate ionic diffusion), and it tends to transform to the thermodynamically more stable $\mathrm{HT}-\mathrm{LiCoO}_{2}$, by starting on the surface, with increasing firing temperature and time.

Although $\mathrm{LT}-\mathrm{LiCoO}_{2}$ with single-valent $\mathrm{Co}^{3+}$ ions exhibits poor ORR activity, the ORR activity could be drastically increased by chemically extracting lithium from $\mathrm{LT}-\mathrm{LiCoO}_{2}$ to give $\mathrm{LT}-\mathrm{Li}_{1-x} \mathrm{CoO}_{2}$. The extraction of lithium from $\mathrm{LT}-\mathrm{LiCoO}_{2}$ results in an oxidation of part of the $\mathrm{Co}^{3+}$ ions to $\mathrm{Co}^{4+}$ ions and a creation of mixed-valent $\mathrm{Co}^{3+/ 4+}$ ions. The strong 
covalency arising from a pinning of the $\mathrm{Co}^{3+/ 4+}: 3 \mathrm{~d}$ states with the top of the $\mathrm{O}^{2-}: 2 \mathrm{p}$ band as shown in Fig. $5 \mathrm{~d}$ along with the high electronic conductivity arising from the partially filled $\mathrm{Co}^{3+/ 4+}: \mathrm{t}_{2 \mathrm{~g}}$ band across the shared edges of the 3-dimensional spinel framework lead to high ORR activity on extracting lithium from $\mathrm{LT}-\mathrm{LiCoO}_{2}$. Thus, the partially delithiated $\mathrm{LT}-\mathrm{Li}_{0.5} \mathrm{CoO}_{2}$, which could actually be a normal, ideal spinel $(\mathrm{Li})_{8 \mathrm{a}}\left[\mathrm{Co}_{2}\right]_{16 \mathrm{~d}} \mathrm{O}_{4}$, with mixed-valent $\mathrm{Co}^{3+/ 4+}$, offers a combination of high ORR and OER activities. Overall, the spinel-type delithiated LT$\mathrm{Li}_{0.5} \mathrm{CoO}_{2}$ behaves as a bifunctional electrocatalyst for OER and ORR in electrochemical devices such as rechargeable lithium-air batteries. Moreover, the chemical delithiation approach presented here to vary the number of $d$ electrons on the transition-metal ion without changing the structure could be explored systematically with other compositions in the future (i) to correlate the d-electron count to ORR and OER activities and (ii) to develop a better understanding of the catalytic mechanisms of ORR and OER.

\section{Methods}

Synthesis and characterization. $\mathrm{IrO}_{2}$ was purchased from Alfa Aesar. The lithiated spinel $\mathrm{LT}-\mathrm{LiCoO}_{2}$ samples were synthesized by a solid-state reaction of stoichiometric amounts of $\mathrm{Li}_{2} \mathrm{CO}_{3}$ and $\mathrm{Co}_{3} \mathrm{O}_{4}$ at $370-400{ }^{\circ} \mathrm{C}$ for various durations (4-7 days), followed by slow furnace cooling. The layered $\mathrm{HT}-\mathrm{LiCoO}_{2}$ sample was synthesized by solid-state reaction of stoichiometric amounts of $\mathrm{Li}_{2} \mathrm{CO}_{3}$ and $\mathrm{Co}_{3} \mathrm{O}_{4}$ at $800^{\circ} \mathrm{C}$ for $24 \mathrm{~h}$, followed by slow furnace cooling. The samples were characterized by X-ray diffraction with $\mathrm{Cu} \mathrm{K} \alpha$ radiation. A Rietveld refinement of the $\mathrm{X}$-ray diffraction data was carried out with the FullProf program. Multi-point Brunauer-Emmett-Teller (BET) surface areas of the samples were collected with an automatic nitrogen gas sorption analyser (NOVA 2000, Quantachrome) using physical adsorption at $77 \mathrm{~K}$.

Chemical extraction of lithium from $\mathrm{LT}-\mathrm{LiCoO}_{2}$ was carried out with a Schlenk line under argon atmosphere at room temperature with the oxidizer $\mathrm{NO}_{2} \mathrm{BF}_{4}$ in acetonitrile medium ${ }^{41}$ :

$\mathrm{LT}-\mathrm{LiCoO}_{2}+\mathrm{xNO}_{2} \mathrm{BF}_{4} \rightarrow \mathrm{LT}-\mathrm{Li}_{1-\mathrm{x}} \mathrm{CoO}_{2}+\mathrm{xLiBF}_{4}+\mathrm{xNO}_{2}(1)$

The amount of lithium extracted was controlled by altering the amount of $\mathrm{NO}_{2} \mathrm{BF}_{4}$ in the reaction medium. Typically, $200 \mathrm{mg}$ of $\mathrm{LT}-\mathrm{LiCoO}_{2}$ was reacted with a specific amount of $\mathrm{NO}_{2} \mathrm{BF}_{4}$ in $20 \mathrm{ml}$ of anhydrous acetonitrile. After reacting for 1 day, the product formed was washed several times with acetonitrile to remove the byproduct $\mathrm{LiBF}_{4}$ and then dried in an air oven at $100{ }^{\circ} \mathrm{C}$. The lithium content in the delithiated sample was analysed by inductively coupled plasma (ICP) analysis.

For STEM analysis, the powders were suspended in isopropanol, sonicated and placed onto a lacey carbon grid. The samples thus prepared were imaged on a JEOL ARM200F TEM/STEM equipped with a CEOS corrector (CEOS GmbH, Heidelberg, Ger.) for the illuminating lenses and a high-angle annular dark-field detector. Some of the high-resolution STEM images were deconvoluted using the maximum entropy method implemented by Ishizuka and $\mathrm{Abe}^{44}$. To simulate the STEM images, atomic models were created in Diamond 3.2i and exported to the high-resolution electron microscopy simulation suite, which is a TEM/STEM simulation software package based on the fast Fourier transform multislice technique ${ }^{45}$. For all the compositions, the multislice simulations were carried out assuming a step scanning size of $0.2 \AA$ (less than the distance to be resolved) and a minimum slice thickness of $1.0 \AA$. The Debye-Waller factor (B), which is related to the mean square of the thermal displacement of an atom from its equilibrium position, was taken from the literature. In particular, the structures and B values for each atomic position were taken from the following: the crystal structure and temperature factors were taken from Meza et al. ${ }^{46}$ for $\mathrm{Co}_{3} \mathrm{O}_{4}$, from our X-ray diffraction data with temperature factors all set to one for $\mathrm{LT}-\mathrm{LiCoO}_{2}$, and from Rosolen et al. ${ }^{47}$ for HT- $\mathrm{LiCoO}_{2}$.

Electrochemical measurements. Typically, $16 \mathrm{mg}$ of the electrocatalyst sample and $3.2 \mathrm{mg}$ of carbon black were dispersed in $8 \mathrm{ml}$ of ethanol/water (1:1 ratio) and $73.2 \mu \mathrm{l}$ of $5 \%$ Nafion solution by ultrasonication for $30 \mathrm{~min}$ to form a homogeneous catalyst ink. The catalyst ink was then coated onto the $\operatorname{RDE}\left(0.196 \mathrm{~cm}^{2}\right)$ at a loading of $0.25 \mathrm{mg}_{\text {oxide }} \mathrm{cm}^{-2}$ disk and dried at room temperature. Before the coating of the catalyst, the glassy carbon electrode $(5 \mathrm{~mm}$ diameter) was polished with $\mathrm{Al}_{2} \mathrm{O}_{3}$ paste $(0.05 \mu \mathrm{m})$ and washed ultrasonically with double-distilled water. All the electrochemical measurements were performed with a saturated calomel electrode as the reference electrode and a platinum foil counter electrode at a scan rate of $20 \mathrm{mV} \mathrm{s}^{-1}$ in $0.1 \mathrm{M} \mathrm{KOH}$ by purging a slow stream of purified oxygen gas towards the working electrode. The rotation speed of RDE was 1,600 r.p.m. for all measurements. Infrared (current $\times$ internal resistance) compensation was applied to linear sweep voltammetry experiments using the Nova software supplied with the Autolab cyclic voltammetry instrument. All potentials reported in this paper are relative to the reversible hydrogen electrode. The mass activity was normalized to the loading of the oxide catalyst.

\section{References}

1. Mallouk, T. E. Water electrolysis: Divide and conquer. Nat. Chem. 5, 362-363 (2013).

2. Suntivich, J., May, K. J., Gasteiger, H. A., Goodenough, J. B. \& Shao-Horn, Y A perovskite oxide optimized for oxygen evolution catalysis from molecular orbital principles. Science 334, 1383-1385 (2011)

3. Turner, J. A. Sustainable hydrogen production. Science 305, 972-974 (2004).

4. Kanan, M. W. \& Nocera, D. G. In situ formation of an oxygen-evolving catalyst in neutral water containing phosphate and $\mathrm{Co}^{2+}$. Science 321, 1072-1075 (2008).

5. Ferreira, K. N., Iverson, T. M., Maghlaoui, K., Barber, J. \& Iwata, S. Architecture of the photosynthetic oxygen-evolving center. Science 303, 1831-1838 (2004).

6. Dismukes, G. C. et al. Development of bioinspired $\mathrm{Mn}_{4} \mathrm{O}_{4}-$ cubane water oxidation catalysts: lessons from photosynthesis. Acc. Chem. Res. 42, 1935-1943 (2009).

7. Manchanda, R., Brudvig, G. W. \& Crabtree, R. H. High-valent oxomanganese clusters: structural and mechanistic work relevant to the oxygen-evolving center in photosystem II. Coord. Chem. Rev. 144, 1-38 (1995).

8. Brimblecombe, R., Bond, A. M., Dismukes, G. C., Swiegers, G. F. \& Spiccia, L. Electrochemical investigation of $\mathrm{Mn}_{4} \mathrm{O}_{4}$-cubane water-oxidizing clusters. Phys. Chem. Chem. Phys. 11, 6441-6449 (2009).

9. Trasatti, S. Electrocatalysis by oxides-attempt at a unifying approach. J. Electroanal.Chem. 111, 125-131 (1980).

10. Gordon, R. B., Bertram, M. \& Graedel, T. E. Metal stocks and sustainability. Proc. Natl Acad. Sci. 103, 1209-1214 (2006).

11. Divisek, J., Malinowski, P., Mergel, J. \& Schmitz, H. Improved components for advanced alkaline water electrolysis. Int. J. Hydrogen Energy 13, 141-150 (1988).

12. Yin, Q. et al. A fast soluble carbon-free molecular water oxidation catalyst based on abundant metals. Science 328, 342-345 (2010).

13. Risch, M. et al. Cobalt-oxo core of a water-oxidizing catalyst film. J. Am. Chem. Soc. 131, 6936-6937 (2009).

14. Jiao, F. \& Frei, H. Nanostructured cobalt and manganese oxide clusters as efficient water oxidation catalysts. Energy Environ. Sci. 3, 1018-1027 (2010).

15. Chou, N. H., Ross, P. N., Bell, A. T. \& Tilley, T. D. Comparison of cobalt-based nanoparticles as electrocatalysts for water oxidation. Chem. Sus. Chem. 4, 1566-1569 (2011).

16. McAlpin, J. G., Stich, T. A., Casey, W. H. \& Britt, R. D. Comparison of cobalt and manganese in the chemistry of water oxidation. Coord. Chem. Rev. 256, 2445-2452 (2012).

17. Bashyam, R. \& Zelenay, P. A class of non-precious metal composite catalysts for fuel cells. Nature 443, 63-66 (2006).

18. Petitto, S. C., Marsh, E. M., Carson, G. A. \& Langell, M. A. Cobalt oxide surface chemistry: The interaction of $\mathrm{CoO}(100), \mathrm{Co}_{3} \mathrm{O}_{4}(110)$ and $\mathrm{Co}_{3} \mathrm{O}_{4}(111)$ with oxygen and water. J. Mol. Catal. A 281, 49-58 (2008).

19. Miles, M. H. Evaluation of electrocatalysts for water electrolysis in alkaline solutions. J. Electroanal. Chem. 60, 89-96 (1975).

20. Singh, R. N., Koenig, J. F., Poillerat, G. \& Chartier, P. Electrochemical studies on protective thin $\mathrm{Co}_{3} \mathrm{O}_{4}$ and $\mathrm{NiCo}_{2} \mathrm{O}_{4}$ films prepared on titanium by spray pyrolysis for oxygen evolution. J. Electrochem. Soc. 137, 1408-1413 (1990).

21. Koza, J. A., He, Z., Miller, A. S. \& Switzer, J. A. Electrodeposition of crystalline $\mathrm{Co}_{3} \mathrm{O}_{4}-\mathrm{a}$ catalyst for the oxygen evolution reaction. Chem. Mater. 24, 3567-3573 (2012).

22. Jiao, F. \& Frei, H. Nanostructured manganese oxide clusters supported on mesoporous silica as efficient oxygen-evolving catalysts. Chem. Commun. 46, 2920-2922 (2010).

23. Kanan, M. W., Surendranath, Y. \& Nocera, D. G. Cobalt-phosphate oxygenevolving compound. Chem. Soc. Rev. 38, 109-114 (2009).

24. Goodenough, J. B. \& Kim, Y. Challenges for rechargeable Li batteries. Chem. Mater. 22, 587-603 (2009).

25. Gummow, R. J., Liles, D. C. \& Thackeray, M. M. Spinel versus layered structures for lithium cobalt oxide synthesised at $400^{\circ} \mathrm{C}$. Mater. Res. Bull. 28, 235-246 (1993).

26. Gummow, R. J., Thackeray, M. M., David, W. I. F. \& Hull, S. Structure and electrochemistry of lithium cobalt oxide synthesised at $400^{\circ} \mathrm{C}$. Mater. Res. Bull. 27, 327-337 (1992).

27. Gummow, R. J. \& Thackeray, M. M. Lithium-cobalt-nickel-oxide cathode materials prepared at $400^{\circ} \mathrm{C}$ for rechargeable lithium batteries. Solid State Ionics 53-56, 681-687 (1992).

28. Rossen, E., Reimers, J. N. \& Dahn, J. R. Synthesis and electrochemistry of spinel LT-LiCoO ${ }_{2}$. Solid State Ionics 62, 53-60 (1993).

29. Garcia, B. et al. The structure of low temperature crystallized $\mathrm{LiCoO}_{2}$. Solid State Ionics 80, 111-118 (1995) 
30. Garcia, B., Farcy, J., Pereira-Ramos, J. P. \& Baffier, N. Electrochemical properties of low temperature crystallized $\mathrm{LiCoO}_{2}$. J. Electrochem. Soc. 144, 1179-1184 (1997).

31. Liang, Yongye et al. $\mathrm{Co}_{3} \mathrm{O}_{4}$ nanocrystals on graphene as a synergistic catalyst for oxygen reduction reaction. Nat. Mater. 10, 780-786 (2011).

32. Choi, J., Alvarez, E., Arunkumar, T. A. \& Manthiram, A. Proton insertion into oxide cathodes during chemical delithiation. Electrochem. Solid-State Lett. 9, A241-A244 (2006).

33. Venkatraman, S. \& Manthiram, A. Synthesis and characterization of P3-Type $\mathrm{CoO}_{2-\delta}$. Chem. Mater. 14, 3907-3912 (2002).

34. Santiago, E. I., Bueno, P. R., Andrade, A. V. C., Paiva-Santos, C. O. \& Bulhões, L. O. S. Quantitative structural analysis of the transition from LT$\mathrm{Li}_{\mathrm{x}} \mathrm{CoO}_{2}$ to $\mathrm{HT}-\mathrm{Li}_{\mathrm{x}} \mathrm{CoO}_{2}$ using the rietveld method: correlation between structure and electrochemical performance. J. Power Sources 125, 103-113 (2004).

35. Wang, G. J. et al. Electrochemical behavior of $\mathrm{LiCoO}_{2}$ in a saturated aqueous $\mathrm{Li}_{2} \mathrm{SO}_{4}$ solution. Electrochim. Acta 54, 1199-1203 (2009).

36. McAlpin, J. G. et al. EPR Evidence for Co(IV) species produced during water oxidation at neutral pH. J. Am. Chem. Soc. 132, 6882-6883 (2010).

37. Rasiyah, P. \& Tseung, A. C. C. The role of the lower metal oxide/higher metal oxide couple in oxygen evolution reactions. J. Electrochem. Soc. 131, 803-808 (1984).

38. May, K. J. et al. Influence of oxygen evolution during water oxidation on the surface of perovskite oxide catalysts. J. Phys. Chem. Lett. 3, 3264-3270 (2012).

39. Gardner, G. P. et al. Structural requirements in lithium cobalt oxides for the catalytic oxidation of water. Angew. Chem. Int. Ed. 51, 1616-1619 (2012).

40. Manthiram, A., Kim, J.-H., Kim, Y. \& Lee, K.-T. Crystal chemistry and properties of mixed ionic-electronic conductors. J. Electroceram. 27, 93-107 (2011).

41. Choi, S. \& Manthiram, A. Chemical synthesis and properties of spinel $\mathrm{Li}_{1-{ }_{\mathrm{x}}} \mathrm{Co}_{2} \mathrm{O}_{4-\delta}$. J. Solid State Chem. 164, 332-338 (2002).

42. Surendranath, Y., Kanan, M. W. \& Nocera, D. G. Mechanistic studies of the oxygen evolution reaction by a cobalt-phosphate catalyst at neutral pH. J. Am. Chem. Soc. 132, 16501-16509 (2010).

43. Wang, L.-P. \& Van Voorhis, T. Direct-coupling $\mathrm{O}_{2}$ bond forming a pathway in cobalt oxide water oxidation catalysts. J. Phys. Chem. Lett. 2, 2200-2204 (2011).
44. Ishizuka, K. \& Abe, E. in: Proc. 13th Eur. Microscopy Cong. Instrument. Methods 1, 117-118 (2004).

45. Ishizuka, K. A practical approach for STEM image simulation based on the FFT multislice method. Ultramicroscopy 90, 71-83 (2002).

46. Meza, M., Alburquenque, D., Ortiz, J. \& Gautier, J. L. Lithium cobalt spinel oxide: a structural and electrochemical study. J. Chil. Chem. Soc. 53, 1494-1497 (2008).

47. Rosolen, J. M., Ballirano, P., Berrettoni, M., Decker, F. \& Gregorkiewitz, M. Structural assessment of the electrochemical performance of $\mathrm{Li}_{\mathrm{x}} \mathrm{CoO}_{2}$ membrane electrodes by X-ray diffraction and absorption refinements. Ionics 3 , 345-355 (1997).

\section{Acknowledgements}

This work was supported by the U.S. Department of Energy, Office of Basic Energy Sciences, Division of Materials Sciences and Engineering under award number DE-SC0005397.

\section{Author contributions}

T.M. carried out the synthesis, characterization and electrochemistry work. A.M designed the material system, initiated and supervised the research work, and involved in the scientific discussions. K.A.J. and P.J.F. carried out the TEM characterization. S.T. synthesized and characterized the chemically delithiated samples. T.M. and A.M. prepared the manuscript.

\section{Additional information}

Supplementary Information accompanies this paper on http://www.nature.com/ naturecommunications

Competing financial interests The authors declare no competing financial interests.

Reprints and permission information is available online at http://npg.nature.com/ reprintsandpermissions/

How to cite this article: Maiyalagan, T. et al. Spinel-type lithium cobalt oxide as a bifunctional electrocatalyst for the oxygen evolution and oxygen reduction reactions. Nat. Commun. 5:3949 doi: 10.1038/ncomms4949 (2014). 